\title{
PERCEPÇÃO DOS USUÁRIOS EM RELAÇÃO À ARBORIZAÇÃO DA AVENIDA CÂNDIDO DE
} ABREU - CURITIBA - PR

Mayssa Mascarenhas Grise Monteiro ${ }^{1}$, Alexandre França Tetto ${ }^{2}$, Daniela Biondi ${ }^{3}$, Raquel Ribeiro De Souza

$$
\text { Silva }^{4} 5
$$

\section{RESUMO}

A arborização de ruas é um componente importante na melhoria da condição ambiental urbana. O objetivo deste trabalho foi verificar a percepção dos usuários da Avenida Cândido de Abreu, Curitiba-PR, em relação à sua arborização. Foi aplicada uma enquete aos transeuntes do local juntamente com um levantamento dos equipamentos urbanos e espécies da arborização de ruas. Foram entrevistados 50 transeuntes e identificadas 123 árvores de 11 diferentes espécies, sendo 86,2\% composto por 4 espécies (Handroanthus albus, Handroanthus chrysotrichus, Handroanthus heptaphylla e Largerstroemia indica). Para os transeuntes, a arborização foi reconhecida principalmente pelos benefícios ecológicos que proporciona. As maiores desvantagem apontadas foram a sujeira, segurança e acessibilidade que podem ser agravados pela presença da arborização. Foi entendido também pelos mesmos que a arborização é de responsabilidade da Prefeitura, e que esta deveria melhorá-la. Quanto aos equipamentos urbanos, foram sugeridas a colocação de lixeiras, melhoria da acessibilidade, das calçadas e da iluminação. A arborização tem papel fundamental na paisagem urbana por suas características ecológicas, sociais e estéticas. Para os transeuntes é essencial que a arborização seja valorizada, respeitada e incorporada nas políticas públicas. Sugere-se uma revitalização na avenida, readequando sua arborização a fim de ressaltar sua importância no local.

Palavras-chave: árvore de rua; vegetação urbana; equipamento urbano.

\section{USER'S PERCEPCION OF CÂNDIDO DE ABREU AVENUE IN RELATION TO URBAN STREET TREES, CURITIBA - PR}

\begin{abstract}
An important component in improving the environmental condition of cities is the vegetation, especially the urban street trees. This study aims to verify the users' perception of Cândido de Abreu Avenue - Curitiba-PR, in relation to its street trees. Was applied a survey to avenue passersby and collecting information about urban equipment and streets trees species. Were inquired 50 passersby and identify 123 trees of 11 different species, of which $87 \%$ were 4 species (Handroanthus albus, Handroanthus chrysotrichus, Handroanthus heptaphylla and Largerstroemia indica). For the passersby, the avenue trees' were mainly recognized for providing ecological benefits. The biggest drawbacks pointed were dirt, security and accessibility that can be aggravated by the trees presence. They understand that street trees are City Hall responsibility witch should improve it. About the urban equipment, the passersby made some suggestions such as placing trash bins, improving accessibility, sidewalks and lighting. Tree planting has a fundamental role in the urban landscape features for their ecological, social and aesthetic. For the passerby, is essential the valorization, respect and incorporation of street trees in urban public policy. It is suggested an avenue revival, adapting the street trees in order to emphasize its importance.
\end{abstract}

Key-words: urban forestry; urban vegetation, urban equipment.

\footnotetext{
${ }^{1}$ Bióloga, Ma. Doutoranda em Engenharia Florestal, UFPR, Curitiba, PR, mayssagrise@ibest.com.br. 2 Engenheiro Florestal, Me. Doutorando em Engenharia Florestal, UFPR, Curitiba, PR, tetto@ufpr.br. ${ }^{3}$ Engenheira Florestal, Prof. ${ }^{a}$ Dra. em Engenharia Florestal, UFPR, Curitiba, PR, dbiondi@ufpr.br.

${ }^{4}$ Bal. Em Turismo. Mestranda em Engenharia Florestal, UFPR, Curitiba, PR, unesp2004@yahoo.com.br.

${ }^{5}$ Bal. Em Turismo. Mestranda em Engenharia Florestal, UFPR, Cur
${ }^{5}$ recebido em 01.06.2012 e acetiopara publicação em 15.06.2013
} 
O crescimento urbano atual é sem precedentes. Na América Latina e Caribe a concentração da população em áreas urbanas intensificou-se nas últimas décadas, convertendo esta região na mais urbanizada do mundo em desenvolvimento. Em 1950, 43\% da população vivia nas áreas urbanas, em 2000 este percentual passou a 75,4\% (FUNDO DE POPULAÇÕES DAS NAÇÕES UNIDAS, 2007).

O Brasil era um país agrícola até os anos 60, com uma taxa de urbanização de 44,7\%. Em 1980, $67,6 \%$ do total da população já vivia em cidades. Entre 1991 e 1996, houve um acréscimo de 12,1 milhões de habitantes urbanos, o que reflete na elevada taxa de urbanização de 78,4\% (INSTITUTO BRASILEIRO DE GEOGRAFIA E ESTATÍSTICA, 1997). O último censo, de novembro de 2010, retrata um país urbano, com 84\% dos brasileiros vivendo nas cidades (INSTITUTO BRASILEIRO DE GEOGRAFIA E ESTATÍSTICA, 2010).

As condições urbano-ambientais têm-se deteriorado de maneira ostensiva em termos de impacto sobre cursos d’água e lençóis freáticos, aterros sanitários, tratamento de resíduos, qualidade do ar e sobre as áreas verdes. Isto somado a catástrofes provocadas por fenômenos ambientais e condições econômicas, institucionais e estruturais incapazes de prevenir e mitigar suas consequências, transforma regiões e centros urbanos em zonas extremamente vulneráveis física e socialmente (PROGRAMA DAS NAÇÕES UNIDAS PARA O MEIO AMBIENTE; PROGRAMA DAS NAÇÕES

\section{UNIDAS PARA OS ASSENTAMENTOS}

HUMANOS, 2004).

Desta forma, um planejamento urbano adequado, tecnicamente bem executado e que resulte na conservação paisagística e em uma convivência harmoniosa dos habitantes com os componentes urbanos torna-se fundamental (COMPANHIA ENERGÉTICA DE MINAS GERAIS, 1996).

A arborização urbana, por sua vez, tem papel importante na melhoria da condição ambiental das cidades e, consequentemente, na melhoria da qualidade de vida de seus habitantes, além de tornar mais efetiva a utilização dos espaços públicos (SHAMS et al., 2009). Considerada um dos mais importantes componentes bióticos da cidade, uma vez que está diretamente relacionado ao conforto ambiental (BIONDI, 2008).

A arborização de ruas é um componente importante na paisagem urbana. Além da função paisagística, as árvores são necessárias porque representam bem estar físico e psíquico proporcionando diversos benefícios ao homem (BIONDI; ALTHAUS, 2005; BIONDI, 2008; CEMIG, 1996; HILU, 1997). Seus benefícios estão relacionados a aspectos ecológicos, sociais e estéticos (BIONDI, 2008).

Os benefícios ecológicos da arborização estão relacionados ao microclima (menor amplitude térmica, maior umidade relativa, menor velocidade do vento e menor velocidade da precipitação pluviométrica); à fauna (pelo fornecimento de flores e abrigos); ao controle da erosão eólica e hídrica do solo; à manutenção da qualidade e quantidade de água; à retenção de poeiras e sólidos em suspenção e à amenização da poluição sonora. 
Os benefícios sociais e estéticos referem-se a uma melhoria da condição emocional e na presença de áreas de convívio, bem como no incremento da arquitetura da paisagem (BIONDI; ALTHAUS, 2005; BIONDI, 2008; CEMIG, 1996; HILU, 1997). Seja a arborização urbana compreendida em sua totalidade (arborização viária e áreas verdes) ou em parcela, como por exemplo, a arborização viária, a análise e o estudo de ambas devem ser pautados em termos quantitativos e qualitativos, pois estas possuem função de homogeneizar e integrar a cobertura vegetal nas cidades (MILANO, 1990).

Para a análise da quantidade de árvores no meio urbano, geralmente são apresentados índices que relacionam o número de espécies arbóreas com o número de habitantes da área estudada, definindo-se assim a quantidade de área verde por habitante. Para o quesito qualidade, as espécies arbóreas são analisadas de acordo com os itens listados para finalidade de planejamento (FURTINI et al., 2010). Tratando-se especificamente de índices quantitativos da arborização viária (ou de calçadas), a Sociedade Brasileira de Arborização Urbana (SBAU), reconhece como ideal a presença de pelo menos 100 indivíduos arbóreos por quilômetro de calçada (PAIVA, 2009). Segundo recomendações técnicas, a frequência dos indivíduos arbóreos que compõe a arborização urbana deve estar abaixo de 10\% (ELETROPAULO, 1995; BIONDI; ALTHAUS, 2005).

Os usuários dos logradores das cidades possuem percepções diversas em relação ao ambiente que utilizam, entretanto, é possível que este ambiente passe despercebido por seus usuários devido à frequência contínua do uso, que favorece a desatenção aos detalhes da paisagem, dentre outros fatores, por esta lhe ser familiar. Os equipamentos urbanos são obras e serviços como condições de acessibilidade, arborização, luminosidade e segurança. Públicos ou de utilidade pública, os equipamento urbanos permitem a plena realização da vida de uma população (FERRARI, 1977).

Assim, para se obter um melhor planejamento e compreensão do ambiente urbano, são necessários estudos que enfoquem a percepção da população em relação ao ambiente, pois no uso cotidiano dos espaços, equipamentos e serviços urbanos, a população sente diretamente o impacto da qualidade ambiental (RIO; OLIVEIRA, 1999).

A percepção ambiental urbana tem como objeto de estudo a cidade. Esses estudos se dão por meio de marcas e sinais decorrentes da relação cotidiana do homem com um espaço específico, os quais se dispersam na paisagem urbana, natural e construída e nos hábitos que a caracterizam. A percepção ambiental pode ser entendida como o estudo da linguagem que o homem desenvolve para intervir na natureza e construir seu espaço (FERRARA, 1999).

O estudo da percepção ambiental é importante uma vez que permite conhecer os indivíduos envolvidos, facilitando a realização de um trabalho com bases locais. Partindo-se da realidade do público alvo é possível identificar como os indivíduos percebem o ambiente em que vivem, suas fontes de satisfação e insatisfação (FAGGIONATO, 2010).

Assim, para um melhor planejamento e compreensão do ambiente urbano, fazem-se necessários estudos que enfoquem a percepção da população em relação ao ambiente, os quais podem ser utilizados como um instrumento de planejamento e gestão de áreas verdes (QUADROS; FREI, 2009). Por sua vez, tais estudos sobre a percepção da população quanto aos 
benefícios trazidos por uma arborização adequada das áreas urbanas tem sido cada vez mais realizados em bairros ou cidades do Brasil (OLIVEIRA, 2005).

O objetivo deste trabalho foi verificar a percepção dos usuários da Avenida Cândido de Abreu,
Curitiba-PR, em relação à arborização viária. Além de realizar a caracterização da arborização, o levantamento dos equipamentos urbanos, e traçar o perfil dos usuários da Avenida Cândido de Abreu.

\section{MATERIAL E MÉTODOS}

\section{Caracterização da área de estudo}

O município de Curitiba (FIGURA 1) sofreu muitas ações que tiveram consequências diretas sobre 0 ambiente da cidade, as quais iniciaram-se no século XIX, com o plantio das primeiras árvores em ruas e praças em 1875. Em 1886 tem-se a criação do Passeio Público e do "Cinturão Verde" no entorno da cidade em 1870. Na década de 1940 iniciaram-se os estudos para a formulação de um Plano Diretor, proposto pelo arquiteto francês Alfredo Agache, valorizando a implantação de praças e parques e a proteção de maciços florestais em áreas particulares. Somente em 1965 a proposta do Plano Agache é revisado e adequado culminando na Lei Municipal n. ${ }^{\circ}$ 2.626/66 que definiu e implantou o Plano Diretor, que dentre suas diretrizes, conduz o crescimento da cidade associado à conservação das áreas verdes diretamente relacionada com a qualidade de vida dos cidadãos (ANDREGUETTO, 2009).

Em 1975 é aprovada a Lei n. ${ }^{\circ} 5.234$ que estabeleceu o zoneamento e o uso do solo para a cidade e criou o Setor Especial de Áreas Verdes, estabelecendo que a conservação das áreas naturais fosse prioritária para o crescimento da cidade
(ANDREGUETTO, 2009). Em 2000 foi realizada a revisão da Lei de Zoneamento, Uso e Ocupação do Solo, e a aprovação da Lei n. ${ }^{\circ}$ 9.804, que criou o Sistema Municipal de Unidades de Conservação (CURITIBA, 2000a), Lei n. ${ }^{\circ}$ 9.805, que criou o Anel de Conservação Sanitário Ambiental (CURITIBA, 2000b) e da Lei n. ${ }^{\circ}$ 9.806, que estabeleceu o Código Florestal do Município de Curitiba (CURITIBA, 2000c). Atualmente, o Programa Biocidade objetiva a manutenção de todas as ações de proteção aos ecossistemas naturais. Dentre seus principais objetivos está a definição de que os Planos de Arborização Viária por Bairro considerem as substituições de espécies exóticas (listadas pelo Decreto Municipal n. ${ }^{\circ}$ 473) por espécies nativas (ANDREGUETTO, 2009).

O município de Curitiba possui uma história de desenvolvimento urbano associado às questões urbano ambientais, sempre focando a arborização urbana à qualidade de vida de seus cidadãos. Assim, a Lei n. ${ }^{\circ}$ 9.800/00 que dispõe sobre o Zoneamento, Uso e Ocupação do Solo do município de Curitiba, divide a Cidade em zonas e setores e aloca o Bairro Centro Cívico como Setor 
Especial do Centro Cívico, conforme o artigo 15 da referida Lei, compreendem áreas para as quais são estabelecidas ordenações especiais de uso e ocupação do solo, condicionadas às suas características locacionais, funcionais ou de ocupação urbanística, já existentes ou projetadas e aos objetivos e diretrizes de ocupação da cidade.

O bairro Centro Cívico, conforme o Decreto n. ${ }^{\circ}$ 774/1975, possui o ponto inicial na confluência da
Rua da Glória e Av. João Gualberto; segue pela Avenida João Gualberto, Praça Dezenove de Dezembro (excluindo-a), Ruas Inácio Lustosa, Mateus Leme, José Sabóia Cortes, Marechal Hermes, Comendador Fontana, da Glória até o ponto inicial (INSTITUTO DE PESQUISAS E PLANEJAMENTO URBANO DE CURITIBA, 2010) (FIGURA 2).

Figura 1. Localização do município de Curitiba

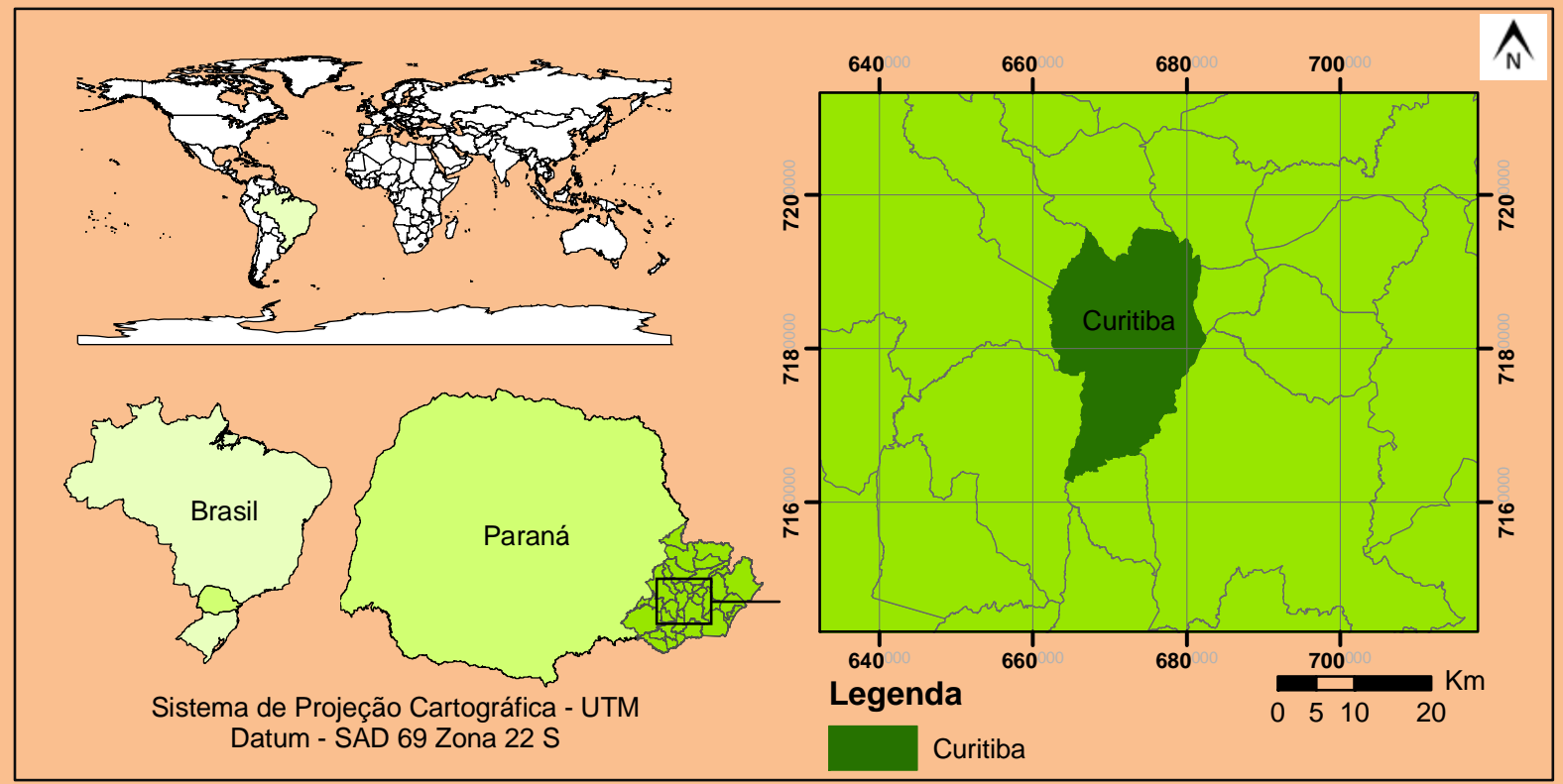

Fonte: Os autores

A área do bairro totaliza 96,50ha, representando 0,22\% do município. Este bairro foi idealizado pelo urbanista Agache na década de 40 e inserido no Plano Diretor de Curitiba daquela época. No sentido literal, Centro Cívico significa o local onde são resolvidos assuntos referentes aos cidadãos. Assim, o Plano Agache concedeu a este bairro características especiais por meio de seus edifícios destinados aos órgãos da administração estadual com um tratamento paisagístico diferenciado. No ano de 1953, na gestão do então governador Bento Munhoz da Rocha Neto, o bairro foi inaugurado e o Estado do Paraná comemorou seu centenário de emancipação política (INSTITUTO DE PESQUISA E PLANEJAMENTO URBANO DE CURITIBA, 2010).

Segundo dados do Instituto de Pesquisa e Planejamento Urbano de Curitiba (2010), em 2000 a densidade demográfica deste bairro era de 49,40 habitantes por hectare, correspondendo a $0,30 \%$ da 
população total do município. Sendo 4.767 habitantes distribuídos em $965.000 \mathrm{~m}^{2}$, o bairro disponibiliza $79.153,63 \mathrm{~m}^{2}$ de áreas verdes entre bosques, jardinetes, largos e praças, que perfazem um total de $16,60 \mathrm{~m}^{2}$ de área verde por habitante e corresponde a $0,10 \%$ do total de área verde do município.

Figura 2. Localização da área de estudo: 1) mapa da cidade de Curitiba indicando o bairro Centro Cívico; 2) imagem de satélite Google indicando a extensão da Avenida Cândido de Abreu abordada nesta pesquisa, do marco zero (A) até a rótula do Palácio das Araucárias (B)

1)

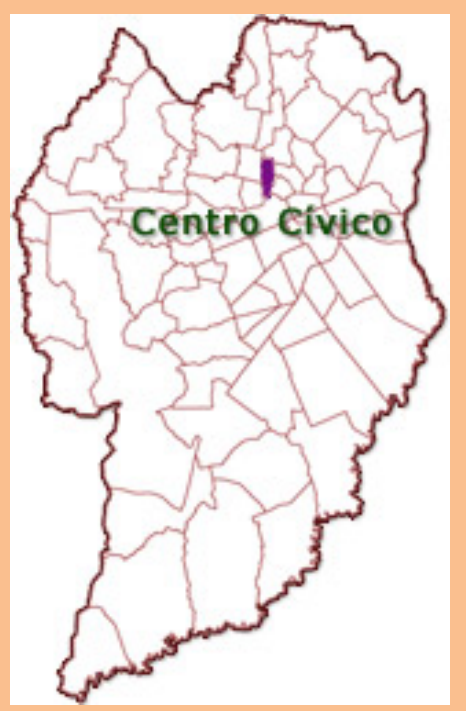

2)

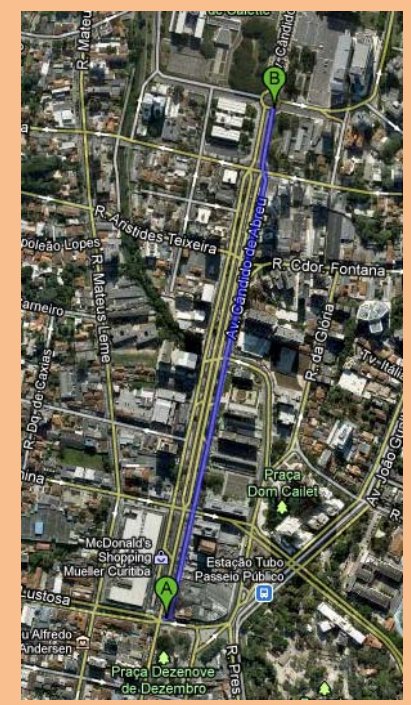

Fonte: IPPUC (2010) e GeoEye (2009), elaborado pelos autores

\section{Procedimentos metodológicos}

A área de estudo foi delimitada como sendo a Avenida Cândido de Abreu, do seu marco inicial até a rótula do Palácio das Araucárias, localizada no Bairro Centro Cívico da Cidade de Curitiba (FIGURA 1). Esta avenida foi escolhida uma vez que é o endereço do Palácio das Araucárias, sede da Prefeitura da Cidade e do Palácio Iguaçu, sede do Governo do Estado do Paraná.

Inicialmente foi realizado o diagnóstico da avenida, estabelecendo o ponto inicial e final da área de estudo, bem como a sua composição de quadras, ruas, canteiros e calçadas. A caracterização da arborização se deu pela identificação de todos os indivíduos arbóreos, suas respectivas espécies e circunferência de fuste. Foi utilizando uma regra de três simples para verificar o número de árvores por metro de extensão da área de estudo.

Os equipamentos urbanos considerados nesta pesquisa foram: banca de jornal e revistas, caixa dos correios, canteiro de flores, ciclovia, fiação elétrica, jardinete, lixeiras, pontos de ônibus e de taxi, posto de informação sobre a cidade (Curitiba 
Informa), relógio e termômetro, e telefones públicos. Os equipamentos urbanos foram quantificados e verificados quanto a existência de conflitos com a arborização.

Na sequência foi aplicado uma enquete (FIGURA

3) com 11 questões fechadas e abertas. As quatro primeiras questões referentes ao perfil do entrevistado, como gênero, idade, grau de escolaridade e profissão. As outras sete questões relacionadas à arborização da avenida.

A enquete foi aplicada em dois dias, no período da manhã (das 8h às 12h) em um sábado e em uma quarta-feira, nos meses de janeiro e março de 2011, respectivamente. Foram abordadas aleatoriamente pessoas que transitavam pela avenida durante os períodos acima citados.

Após a coleta de dados, as respostas da enquete foram tabuladas em planilha de dados comum, e analisadas segundo o percentual de preferência dos entrevistados. As respostas foram ainda confrontadas com o resultado do levantamento realizado para a arborização e para os equipamentos urbanos presentes na avenida.

\section{RESULTADOS E DISCUSSÃO}

A extensão da avenida, analisada neste estudado, foi de aproximadamente $900 \mathrm{~m}$ divididos em seis quadras formadas por três vias para automóveis, duas calçadas laterais e duas centrais.
Os equipamentos urbanos encontrados na avenida totalizaram 60 unidades conforme apresentado na Tabela 1. Não foram identificados placas de sinalização em conflito com a arborização.

Figura 3. Questões abordadas na enquete aplicada aos transeuntes da Avenida Cândido de Abreu - Curitiba-PR

\section{Gênero do entrevistado. \\ ( ) masculino ( ) feminino \\ Grau de escolaridade do entrevistado: \\ ( ) analfabeto \\ ( ) ensino fundamental incompleto / ( ) completo \\ ( ) ensino médio incompleto / ( ) completo \\ ( ) ensino superior completo / ( ) incompleto}

Profissão:

Qual a sua relação com a Avenida Cândido de Abreu?

( ) Morador

( )Trabalho

( ) Transeunte frequente

( ) Transeunte raro

( ) Primeira vez visitando a rua

( ) Turista

Como você considera a arborização da Avenida Cândido de Abreu? 
( ) muito arborizada

( ) adequadamente arborizada

( ) pouco arborizada

Quais as vantagens que você observa na arborização da Avenida Cândido de Abreu?

( ) benefícios estéticos

( ) benefícios ecológicos

( ) benefícios sociais

Quais as desvantagens que você observa na arborização da Avenida Cândido de Abreu?
( ) sujeira
( ) acessibilidade
( ) segurança

A que órgão você encaminharia suas reclamações referentes à arborização da Avenida Cândido de Abreu?

( ) prefeitura municipal

( ) COPEL

( ) IAP

Você considera adequadas as espécies plantadas nas calçadas da Avenida Cândido de Abreu?

( ) Sim ( ) Não

Na sua opinião, o que deveria ser feito para melhorar a arborização da Avenida Cândido de Abreu?

( ) implantar mais árvores

( ) fazer manutenção e realizar podas de forma e época corretas

( ) fazer um trabalho de conscientização ecológica sobre arborização

Você considera a arborização importante?

( ) Sim ( ) Não

Tabela 1. Levantamento dos equipamentos urbanos presentes ao longo da Avenida Cândido de Abreu - CuritibaPR

\begin{tabular}{l|c}
\hline Equipamentos urbanos & Quantidade \\
\hline Banca de jornal e revista & 1 \\
\hline Caixa dos correios & 2 \\
\hline Canteiro de flores & 1 \\
\hline Ciclovia $\left(^{*}\right)$ & - \\
\hline Fiação elétrica $\left(^{*}\right)$ & 1 \\
\hline Jardinete & 1 \\
\hline Lixeira & 23 \\
\hline Ponto de ônibus - Estação Tubo & 5 \\
\hline Ponto de ônibus & 4 \\
\hline Ponto de táxi & 2 \\
\hline Posto de informação: Curitiba Informa & 1 \\
\hline Relógio e termômetro & 1 \\
\hline Telefone público & 18 \\
\hline Total & $\mathbf{6 0}$ \\
\hline NOTA: $\left.{ }^{*}\right)$ Não quantificados. &
\end{tabular}


Foram identificadas 123 árvores de 11 diferentes espécies, sendo observada a predominância de 4 espécies: Handroanthus albus, Handroanthus chrysotrichus, Handroanthus heptaphyllus e Largerstroemia indica (TABELA 2). Os canteiros das árvores, ou seja, as áreas permeáveis na base das árvores, apresentaram-se de forma circular e com média de $30 \mathrm{~cm}$ de circunferência. Esta área é muito pequena se considerado o recomendável de no mínimo um metro quadrado e ainda não possui forma retangular e contínua (BIONDI; ALTHAUS, 2005; MATOS; QUEIROZ, 2009).

Para tornar as árvores menos susceptíveis à pragas e doenças e não diluir o seu efeito estético, sugere-se que seja usada uma mesma espécie em pelo menos uma mesma quadra (BIONDI; ALTHAUS, 2005). Isto não foi observado ao longo da avenida. As quadras apresentam as diferentes espécies plantadas aleatoriamente, ainda que haja uma predominância do gênero Handroanthus, o qual representa aproximadamente 55\% dos exemplares amostrados, e da espécie Largerstroemia indica (32\%).

Segundo resultados obtidos por Milano ${ }^{1}$ citado por Biondi e Althaus (2005), as espécies Handroanthus albus, Handroanthus chrysotricha e Largerstroemia indica demonstraram ser altamente susceptíveis à pragas e doenças. Estas espécies foram justamente as que representaram cerca de 87\% das árvores amostradas e com diâmetro médio de árvores adultas, 48 e 39 cm respectivamente. Portanto, caso haja necessidade de remoção destas árvores já adultas, devido à pragas ou doenças, a arborização da Avenida ficaria muito comprometida.

\footnotetext{
${ }^{1}$ MILANO, M. S. Avaliação e análise da arborização de ruas de Curitiba. Curitiba, 1984. Dissertação Mestrado. Universidade Federal do Paraná. Setor de Ciências Agrárias. Curso de Pós-graduação Engenharia Florestal.
} 
Tabela 2. Caracterização da arborização da Avenida Cândido de Abreu - Curitiba-PR

\begin{tabular}{|c|c|c|c|c|}
\hline Nome científico & Nome popular & $\begin{array}{l}\text { Número de } \\
\text { árvores }\end{array}$ & $\begin{array}{l}\text { Diâmetro } \\
\text { médio }(\mathbf{c m})\end{array}$ & Origem \\
\hline Handroanthus albus & Ipê-amarelo & 2 & \multirow{3}{*}{47,9} & Nativa \\
\hline Handroanthus chrysotrichus & Ipê-amarelo & 3 & & Nativa \\
\hline Handroanthus heptaphyllus & Ipê-roxo & 62 & & Nativa \\
\hline Largerstroemia indica & Extremosa & 39 & 39,1 & Exótica \\
\hline Araucaria angustifolia & Pinheiro-do-Paraná & 8 & 114,5 & Nativa \\
\hline Tipuana tipu & Tipuana & 3 & 121,3 & Nativa \\
\hline Cassia leptophylla & Canafístula & 2 & 83 & Nativa \\
\hline Erythrina falcata $^{(*)}$ & Corticeira & 1 & 307 & Nativa \\
\hline Nerium oleander & Espirradeira & 1 & 34 & Exótica \\
\hline Schinus terebinthifolius & Aroeira & 1 & 59 & Nativa \\
\hline Syagrus romanzoffiana & Jerivá & 1 & 118 & Nativa \\
\hline Total & & 123 & & \\
\hline
\end{tabular}

NOTA: $\left.{ }^{*}\right)$ Situada em um jardinete.

Apenas duas espécies amostradas são exóticas: Largerstroemia indica e Nerium oleander, as quais representam 32\% das árvores amostradas. Entretanto, estas espécies não foram inseridas na lista de espécies florestais exóticas invasoras do Município de Curitiba, anexa ao Decreto n. ${ }^{\circ}$ 473/2008. Assim estas árvores não serão substituídas por espécies nativas. Até mesmo porque a Largerstroemia indica foi apontada em 1992 como a espécie mais plantada em Curitiba e possui as características ideais para o plantio na área urbana, tais como porte pequeno e, portanto não possui restrições ao seu uso sob a rede aérea de fiação elétrica, raiz pivotante sendo recomendada para calçadas estreitas e crescimento rápido (BIONDI; ALTHAUS, 2005). Biondi e Althaus (2005) ressaltam ainda que não se deve excluir a introdução de espécies exóticas uma vez que a cidade é um ambiente antrópico e com diferentes influencias culturais. Já Nerium oleander além de ser arbustiva, ou seja, não adequada para calçadas, é uma espécie tóxica (BIONDI, 2008).
Todas as árvores amostradas apresentaram diâmetro de tronco correspondente ao esperado para indivíduos adultos de cada espécie. Portanto, não foram identificados indivíduos jovens ou plantios recentes ao longo da avenida.

Durante os dois dias de entrevistas, foram obtidos 50 questionários respondidos. Do total de respondentes, 62\% foram mulheres. A maioria (52\%) com idade entre 20 e 39 anos e ensino médio completo (58\%). Dos 58\% com ensino médio completo, 32\% ingressaram em um curso superior, sendo que $16 \%$ já o completaram. Quanto à profissão, 58\% exercem atividades relacionadas à área de humanas e 26\% ainda são estudantes.

A maioria dos entrevistados (38\%) declarou trabalhar na avenida, seguido por "transitar raramente” (28\%) e frequentemente (26\%). Isto corrobora com o perfil da avenida, quase exclusivamente composta de prédios comerciais e pelas secretarias governamentais. Apenas um morador e um turista foram entrevistados. Ainda que a avenida esteja a poucos metros do Museu 
Oscar Niemayer, um marco da arquitetura nacional e um dos pontos turísticos mais importantes e impressionantes da Cidade.

A avenida foi considerada adequadamente arborizada por $52 \%$ dos entrevistados, $46 \%$ a consideraram pouco arborizada e somente $2 \%$ muito arborizada. Segundo dados do Instituto de Pesquisa e Planejamento Urbano de Curitiba (2010), o bairro apresenta $16,60 \mathrm{~m}^{2}$ de área verde por habitante. Isto é superior ao sugerido pela Sociedade Brasileira de Arborização Urbana (SBAU; 1996) que é de $15 \mathrm{~m}^{2} /$ hab. Como esta pesquisa avaliou apenas as árvores de uma avenida do bairro, foi feita uma estimativa do número de árvores por metro de extensão da avenida, resultando em cerca de uma árvore a cada $8 \mathrm{~m}$. Levando-se em conta que a avenida possui aproximadamente 50m de largura e é composta por quatro calçadas paralelas, estas árvores acabam espaçadas e este número acaba superestimado. Apesar da maioria dos entrevistados considerar a avenida adequadamente arborizada, o espaçamento entre as árvores acaba sendo muito superior à projeção da copa das espécies, as quais na maioria não ultrapassa $10 \mathrm{~m}$.

Quanto aos benefícios proporcionados pela arborização, os entrevistados deveriam colocar em ordem decrescente de importância, seu entendimento sobre os aspectos ecológicos, estéticos e sociais agregados à arborização da avenida. A maioria dos entrevistados (68\%) consideraram os aspectos ecológicos como o principal benefício proporcionado pela arborização. Em segundo lugar, 42\% citaram os aspectos estéticos e em terceiro lugar 44\% citaram os aspectos sociais. Estes resultados demonstram que existe um entendimento dos transeuntes da importância da arborização na cidade, o que pode a longo prazo estimular investimentos em políticas públicas adequadas ao planejamento, implantação, manejo e monitoramento da arborização. Uma vez que os benefícios ecológicos são sem dúvida os que mais interferem positivamente na qualidade de vida dos cidadãos.

Este mesmo resultado também foi encontrado em outras pesquisas, como a de Malavasi e Malavasi (2001) ao pesquisar a percepção da população de Cândido Rondon - PR, verificaram que mais de 90\% da população considerava os benefícios ecológicos os mais significativos em relação à arborização. O mesmo foi observado por Roppa et al. (2007), Araújo et al. (2010) e Quadros e Frei (2009). Alguns trabalhos, entretanto, demonstram que os aspectos estéticos, relacionados à beleza proporcionada pelo verde e colorido das flores, seria a principal função da arborização (TEIXEIRA et al.; 2009).

Além destes, os entrevistados deveriam elencar as desvantagens da arborização na avenida relacionadas aos aspectos de sujeira, acessibilidade e segurança. A maior desvantagem citada foi a sujeira, apontada por $45 \%$ dos entrevistados, seguido pela acessibilidade (40\%) e pela segurança (38\%). A sujeira e a segurança são dois aspectos negativos que os transeuntes relacionam diretamente à arborização de ruas, conforme contatado por diversos autores como Malavasi e Malavasi (2001) e Roppa et al. (2007). A acessibilidade foi destacada pelos entrevistados, principalmente pelas saliências criadas pelas raízes das árvores nas calçadas, dificultando a passagem ou oferecendo risco de queda aos transeuntes, o mesmo foi observado por Roppa et al. (2007). 
A arborização de ruas é de responsabilidade das prefeituras municipais, conforme estabelece 0 Código Florestal (Lei n. ${ }^{\circ}$ 7.803/89, art. 2). A Constituição Federal atribui competência exclusiva aos municípios para legislarem sobre as matérias de interesse local relacionadas às normas de uso e ocupação do solo, bem como o ordenamento urbanístico. As restrições urbanísticas devem ser utilizadas como instrumento do poder público integrando conceitos de desenvolvimento urbano, preservação ambiental e proteção do patrimônio cultural (OLIVEIRA; SANTOS, 2004).

Em relação aos órgãos que encaminhariam uma solicitação a respeito da arborização, 68\% se dirigiria à Prefeitura Municipal de Curitiba, 30\% ao Instituto Ambiental do Paraná (IAP) e apenas 2\% a Companhia Paranaense de Energia (COPEL). Assim, parece haver um entendimento dos transeuntes de que a responsabilidade da via e seus componentes, inclusive a árvore, é de responsabilidade da Prefeitura.

Vários artigos vêm demonstrando tal entendimento. Resultados obtidos por Malavasi e Malavasi (2001) e Roppa et al. (2007) corroboram com os aqui apresentados. Teixeira et al. (2009) verificaram em três loteamentos particulares em Santa Maria - RS, que a população gostaria que ela própria fosse a responsável pelo plantio e pela manutenção das calçadas, uma vez que não viam o poder público executando tal dever. Entretanto, tal posicionamento reflete a opinião da população de uma área de loteamentos particulares e residenciais. Consideraram adequadas as espécies presentes na avenida, 64\% dos entrevistados. Diversos entrevistados mencionaram o porte exagerado da espécie Araucaria angustifolia para o local, alegando principalmente o perigo relacionado à quedas de seus galhos.

Quando questionados quais as melhorias que poderiam ser feitas para ressaltar a importância da avenida, $48 \%$ citaram a falta de lixeiras nas calçadas, entretanto, as lixeiras foram os equipamentos urbanos encontrados em maior número ao longo da avenida. Cerca de $40 \%$ citou a arborização, entretanto a maioria dos entrevistados considerou a avenida adequadamente arborizada.

Na Figura 3 são apresentados os itens listados pelos entrevistados em porcentagem, cabe ressaltar que esta questão foi aberta e cada entrevistado poderia dar quantas respostas achasse pertinente.

Figura 3. Melhorias sugeridas para ressaltar a importância da Avenida Cândido de Abreu - Curitiba-PR

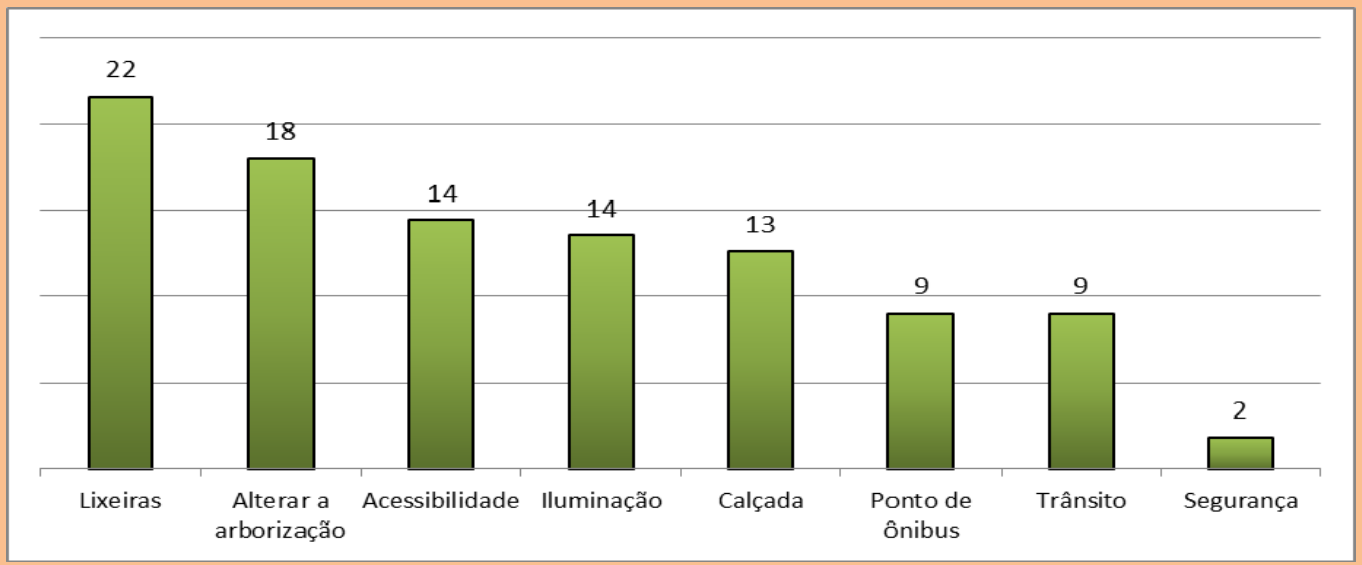


A arborização da Avenida Candido de Abreu foi caracterizada pela predominância do gênero Handroanthus e da espécie Largerstroemia indica, os quais representaram $87 \%$ dos exemplares amostrados

A arborização da avenida é reconhecida pelos entrevistados principalmente pelos benefícios ecológicos que proporciona ao ambiente e à população. As maiores desvantagem apontadas pela população estão relacionadas à problemas com sujeira, segurança e acessibilidade que podem ser agravados na presença de arborização.

Os entrevistados entendem que a arborização é de responsabilidade da Prefeitura, e que esta deveria melhora-la, seja com o plantio de mais árvores ou com a alteração e/ou manutenção das árvores existentes. Outras sugestões dos entrevistados são a colocação de lixeiras, a melhoria da acessibilidade, das calçadas e da iluminação, também quesitos de responsabilidade da Prefeitura. Pode-se observar, pelas características distintas das espécies plantadas aleatoriamente ao longo da avenida, que a arborização ocorreu sem planejamento, e isto é evidenciado pela população que sugere melhorias na arborização da Avenida.

A arborização tem papel fundamental na paisagem urbana por suas características ecológicas, sociais e estéticas. O entendimento disto por parte da população é essencial para que a arborização seja valorizada, respeitada e principalmente incorporada nas políticas públicas urbanas.

Sugere-se que seja feita uma revitalização na avenida, readequando sua arborização de modo que esta contribua para ressaltar a sua importância e atenda aos anseios e demandas da população.

\section{REFERÊNCIAS BIBLIOGRÁFICAS}

ANDREGUETTO, J. A. Projeto Biocidade - restauração e conservação da biodiversidade urbana e a preservação de áreas naturais. In: VI CONGRESSO BRASILEIRO DE UNIDADES DE CONSERVAÇÃO, 6., 2009, Curitiba. Anais... Curitiba: Rede Nacional Pró-Unidades de Conservação, Fundação O Boticário de Proteção à Natureza, 2009. 1CD-ROM.

ARAÚJO, J. de L. O.; ARAÚJO, A. C de.; ARAÚJO, A. C. de. Percepção ambiental dos residentes do bairro Presidente Médici em Campina Grande - PB, no tocante à arborização local. REVSBAU, Piracicaba, v. 5, n. 2, p. 67 - 81, 2010.

BIONDI, D.; ALTHAUS, M. Árvores de rua de Curitiba: cultivo e manejo. Curitiba: FUPEF, 2005.

BIONDI, D. Arborização urbana: aplicação à educação ambiental nas escolas. Curitiba, 2008. 
COMPANHIA ENERGÉTICA DE MINAS GERAIS (CEMIG) Manual de arborização. Belo Horizonte: Superintendência do Meio Ambiente, 1996.

CURITIBA. Lei n. ${ }^{\circ}$ 9.804, de 03 de janeiro de 2000a. Cria o Sistema de Unidades de Conservação do Município de Curitiba e estabelece critérios e procedimentos para implantação de novas Unidades de Conservação. Disponível em: <http://avenida.curitiba.pr.gov.br/conteudo/legislacao-smma-secretaria-municipal-do-meioambiente>. Acesso em: 02/05/2011.

. Lei n. ${ }^{\circ}$ 9.805, de 03 de janeiro de 2000b. Cria o Setor Especial do Anel de Conservação Sanitário Ambiental e dá outras providências. Disponível em: <avenida.curitiba.pr.gov.br/conteudo/legislacao...smu.../220>. Acesso em: 02/05/2011.

. Lei n. 9.806, de 03 de janeiro de 2000c. Institui o Código Florestal do Município de Curitiba, e dá outras providências. Disponível em: <avenida.curitiba.pr.gov.br/conteudo/legislacao...smu.../220>. Acesso em: 02/05/2011.

ELETROPAULO. Guia de planejamento e manejo da arborização urbana. São Paulo: Eletropaulo, Cesp, CPFL, 1995. 40 p.
FAGGIONATO,
S. Percepção
ambiental.
Disponível
em:

<http://educar.sc.usp.br/biologia/textos/m_a_txt4.html>. Acesso em: 06/12/2010.

FERRARA, L. D’A. As cidades ilegíveis: percepção ambiental e cidadania. In: DEL RIO, V.; OLIVEIRA, L. Percepção ambiental: a experiência brasileira. São Paulo: Studio Nobel, 1999.

FERRARI, C. Curso de planejamento municipal integrado. São Paulo: Livraria

Pioneira Editora, 1977.

FUNDO DE POPULAÇÕES DAS NAÇÕES UNIDAS (UNFPA) Relatório sobre a Situação da População Mundial 2007. Disponível em: <http://avenida.unfpa.org.br/relatorio2007/swp_mensagem.htm>. Acesso em: $12 / 07 / 2010$

FURTINI, K. V. et al., Índice de áreas verdes da cidade de lavras, MG. In: CONGRESSO BRASILEIRO DE ARBORIZAÇÃO URBANA, 14, 2010, Bento Gonçalves. Anais... Rio Grande do Sul: SBAU, 2010.

HILU, A. C. Manejo del arbolado urbano. Universidad Autonoma Metropolitana. México, 1997.

INSTITUTO BRASILEIRO DE GEOGRAFIA E ESTATÍSTICA (IBGE) Contagem da População, 1996. Rio de Janeiro, 1997.

Censo 2010: população do Brasil é de 190.732 .694 pessoas. Disponível em:

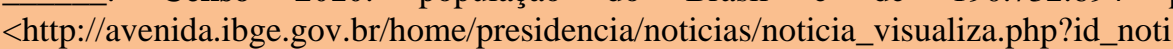

cia=1766\&id_pagina=1>. Acesso em: 06/12/2010.

INSTITUTO DE PESQUISA E PLANEJAMENTO URBANO DE CURITIBA (IPPUC) Curitiba em dados. Disponível em: $<$ http://avenida.ippuc.org.br/Bancodedados/Curitibaemdados/Curitiba_em_dados_Pesquisa.asp?ampliar=n\%C3 \%A3o>. Acesso em: 06/12/2010.

MALAVASI, U. C.; MALAVASI, M. M. Avaliação da arborização urbana pelos residentes - estudo de caso em Marechal Cândido Rondon. Revista Ciência Florestal. v.11, n.1, p. 189 -193, 2001.

MATOS, E.; QUEIROZ, L. P. Árvores para cidades. Salvador: Ministério Público do Estado da Bahia, 2009. 
MILANO, M. S. Avaliação quati-qualitativa e manejo da arborização urbana: exemplo de Maringá - PR. 120 f. Tese (Doutorado em Engenharia Florestal) - Setor de Ciências Agrárias, Universidade Federal do Paraná, Curitiba, 1988.

OLIVEIRA, E. Z. A percepção ambiental da arborização urbana dos usuários da avenida Afonso Pena entre as ruas Calógeras e Ceará da cidade de Campo Grande- MS. 2005. 125 f. (Dissertação). UNIDERP, Campo Grande, 2005.

OLIVEIRA, C. A. de SANTOS, C. J. F. Florestas urbanas: normas de uso e ocupação do solo para proteção de unidades de Conservação nas cidades. In: IV CONGRESSO BRASILEIRO DE UNIDADES DE CONSERVAÇÃO, 1., 2004, Curitiba. Anais... Curitiba: Rede Nacional Pró-Unidades de Conservação, Fundação O Boticário de Proteção à Natureza, 2004. 1 v. p. 542 - 549.

PAIVA, A. V. Aspectos da arborização urbana do centro de Cosmópolis - SP. REVSBAU, Piracicaba , v. 4, n. 4, p. 17 - 31, 2009.

PROGRAMA DAS NAÇÕES UNIDAS PARA O MEIO AMBIENTE (PNUMA); PROGRAMA DAS NAÇÕES UNIDAS PARA OS ASSENTAMENTOS HUMANOS (UN-HABITAT), Estratégia urbanoambiental para a América Latina e o Caribe. 2004.

QUADROS, L. S. de; FREI, F. Percepção ambiental dos residentes da cidade de Assis - SP com relação à arborização viária da Avenida Rui Barbosa. REVSBAU, Piracicaba, v. 4, n .2, p.16 - 34, 2009.

RIO, V.; OLIVEIRA, L. (org). Percepção ambiental: a experiência brasileira. 2 ed. São Paulo: UFSCAR/ Studio Nobel, 1999.

ROPPA; C., FALKENBERG J. R.; STANGERLIN, D. M.; BRUN, F. G. K.; BRUN, E. J.; LONGHI, S. J. Diagnóstico da percepção dos moradores sobre a arborização urbana na Vila Estação Colônia - bairro Camobi, Santa Maria. REVSBAU, v. 2, n. 2, 2007.

SOCIEDADE BRASILEIRA DE ARBORIZAÇÃO URBANA - SBAU. "Carta a Londrina e Ibiporã". Boletim Informativo, v.3 , n.5, p.3, 1996.

SHAMS, J. C. A.; GIACOMELI, D. C.; SUCOMINE, N. M. Emprego da arborização na melhoria do conforto térmico nos espaços livres públicos. REVSBAU, Piracicaba, n. 4, v. 4, p. 1 - 16, 2009.

TEIXEIRA, I. F.; SANTOS, N. R. Z. dos; BALEST, S. de S. Percepção ambiental dos moradores de três loteamentos particulares em Santa Maria (RS) quanto a arborização de vias públicas. REVSBAU, Piracicaba, v. 4, n. 1, p. 58 - 78, 2009. 